INDO GLOBAL JOURNAL OF

PHARMACEUTICAL SCIENCES

ISSN 2249- 1023

\title{
Novel Electrode Based on Ruthenium Oxide and Polyaniline Anode for Improved Performance of Microbial Fuel Cells
}

\author{
Geetanjali ${ }^{1}$, Radha Rani ${ }^{1}$, Sanjay Kumar ${ }^{1,2^{*}}$ \\ ${ }^{1}$ Department of Biotechnology, Motilal Nehru National Institute of Technology Allahabad, Allahabad 211004, India \\ ${ }^{2}$ Department of Biochemical Engineering, Indian Institute of Technology (Banaras Hindu University), Varanasi-221 005, Uttar Pradesh, \\ India
}

Address for Correspondance: Sanjay Kumar, sanjaykr27@mnnit.ac.in

Keywords

Microbial Fuel

Cell; Nanoparticles;

Polyaniline; Power

Density.

\begin{abstract}
Microbial fuel cells (MFCs) are a promising technology capable of directly converting into electricity from the abundant biomass on the earth. This work described the synergistic effect of ruthenium oxide $(\mathrm{RuO} 2)$ nanoparticles and/or polyaniline (PANI) on carbon paper (CP) based anode for better bacterial attachment and enhance electron conductivity. The obtained macroporous structure $\mathrm{RuO} 2$ and PANI was characterized by scanning electron microscopy (SEM) and X- ray diffraction (XRD). Cyclic voltammetry (CV) results demonstrated that the $\mathrm{CP}$ coated with $\mathrm{RuO} 2$ and/or PANI has a larger active area than plain $\mathrm{CP}$ electrodes. To test microbial electricity generation, the $\mathrm{CP}, \mathrm{CP} / \mathrm{RuO} 2, \mathrm{CP} / \mathrm{PANI}$ and $\mathrm{CP} / \mathrm{RuO} 2 / \mathrm{PANI}$ electrodes were used as anodes in the MFC system with the same projected geometric surface area of $9 \mathrm{~cm} 2$ were poised at $0.2 \mathrm{~V}$. Inoculum from activated sludge sample inoculated into MFCs with glucose as the sole electron donor. Electrochemical impedance spectra (EIS) results provided evidence that there was a substantial improvement in electron transfer between the microbes and the anode as well as electrical conductivity. The differences in electricity generation and power density from these four electrodes were confirmed by polarization and power density curves. The power output of a single chamber microbial fuel cell (MFC) constructed from the carbon paper anode and mixed bacterial culture increases drastically with the $\mathrm{CP} /$ $\mathrm{RuO} / \mathrm{PANI}$ modification. The power density and OCP were experimentally measured as $923 \pm 5 \mathrm{mV}$ and $1123 \pm 20 \mathrm{~mW} / \mathrm{m} 2$, respectively, which were approximately 15 times greater than the plain carbon paper based MFCs. More bacteria were observed to adhere attached on the CP/ RuO2/PANI anode than on the other anode during the working of the MFC. This strategy provides an easy scale-up, simple and controllable method for the preparation of high-performance and moderate-cost MFC anodes. (C) 2016 iGlobal Research and Publishing Foundation. All rights reserved.
\end{abstract}

Conference Proceedings: International Conference on Advances in Plant and Microbial Biotechnology (PMB2017); JIIT, Noida: February 02-04, 2017

Indo Global Journal of Pharmaceutical Sciences( ISSN 22491023 ; CODEN- IGJPAI; NLM ID: 101610675) indexed and abstracted in EMBASE(Elsevier), SCIRUS(Elsevier),CABI, CAB Abstracts, Chemical Abstract Services(CAS), American Chemical Society(ACS), Index Copernicus, EBSCO, DOAJ, Google Scholar and many more. For further details, visit http://iglobaljournal.com 